\title{
INTERPARIETAL WALL HERNIA: A CASE REPORT
}

\author{
S. Venkata Reddy ${ }^{1}$, K. Veera Venkata Satyanarayana², N. S. Ayyappa Morla ${ }^{3}$
}

\section{HOW TO CITE THIS ARTICLE:}

S. Venkata Reddy, K. Veera Venkata Satyanarayana, N. S. Ayyappa Morla. "Interparietal Wall Hernia: A Case Report". Journal of Evolution of Medical and Dental Sciences 2015; Vol. 4, Issue 39, May 14;

Page: 6898-6900, DOI: $10.14260 /$ jemds/2015/1001

\begin{abstract}
An-inter parietal hernia is a rare form of hernia seen in the inguinal region, represent a problem in the differential diagnosis of conditions functional in the inguinal region. Its pathogenesis is not well understood. Preoperative diagnosis of obstructing inter parietal hernia is difficult. Once considered, its diagnosis and treatment is straightforward. We present a case of inter parietal wall hernia.
\end{abstract}

KEYWORDS: Hernia, parietal wall.

INTRODUCTION: Inter parietal hernias are quite rare hernias occurring at anterior abdominal wall at various anatomical (Parietal) plans in the inguinal region. Since it is a rare condition, it is generally reported as sporadic cases. The hernia sac passes between musculo aponeurotic layers of the anterior abdominal wall. There is often a problem of differential diagnosis with spigelian hernia.

CASE REPORT: A 55 year old female patient presented to our surgery department with history of pain in the right iliac fossa for last 6 months. The pain was dragging in nature aggravated by straining, relieved by medication. There was no fever, nausea, vomiting or constipation. On physical examination a tender palpable lump is present in the right iliac fossa which is irreducible, nonmobile, there was no expansile impulse on cough. No abdominal distention present. Ultra sound of abdomen and pelvis shows hernial sac with omentum in between muscle layers in the inguinal region. On surgical exploration a hernial sac was found in between external oblique aponeurosis and internal oblique muscle. [Figure 1] Musculo-aponeurotic structures were weak. After dissection of the sac herniotomy and resection of omentum [Figure 2] was performed. The defect was closed and hernioplasty was performed with polypropylene mesh. [Figure 2] The post-operative period was uneventful and showed no recurrence 6 months after surgery.

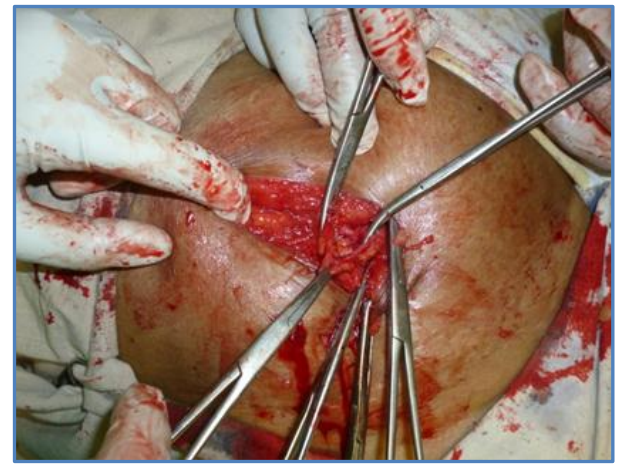

Fig. 1: Defect in between the layers of Anterior abdominal wall

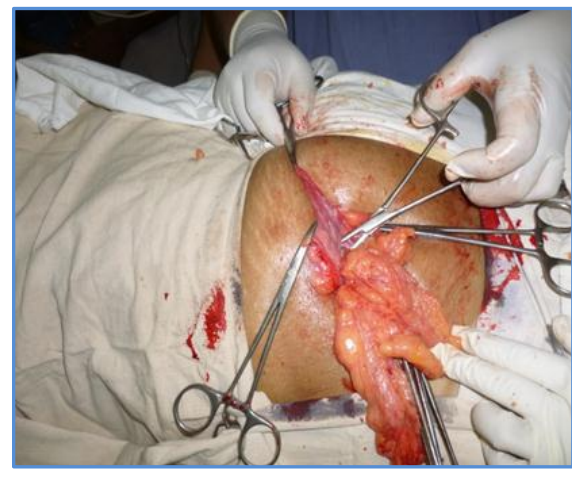

Fig. 2: Hernial Sac with omentum as content 


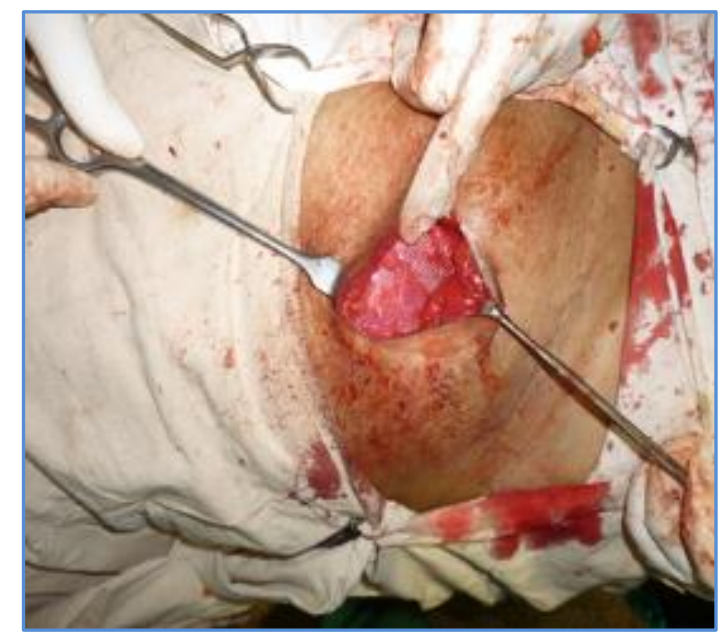

\section{Fig. 3: Hernioplasty with polypropylene}

DISCUSSION: Bartolin first described inter parietal hernia in 1661.[1] Its definition has not changed since then, however, three subtypes have been described recently. The three subtypes are pre peritoneal (Between peritoneum and transversalis fascia), interstitial (Between transversalis fascia and transverse, internal oblique or external oblique muscles), and superficial (Between external oblique and skin or within aponeurosis of the inguinal region).[2] Lower and Hicken ${ }^{[3]}$ reported in their series, which is still the largest published one, that the inter parietal hernias among all inguinal hernias should be as frequent as $0.01-1.6 \%$. They also commented that the interstitial subtype comprised of $60 \%$ of the cases, while the other two subtypes occurred $29 \%$ each. It is reported that the interparietal hernia is predominant in males.[1]

The interparietal hernias are frequently confused with inguinal hernias. The diagnosis is usually determined during the operation, as it was the case in our patient. Koot ${ }^{[4]}$ discussed whether the interparietal hernias, which frequently presents with small bowel obstruction and appears at a level above inguinal ligament, are a rare variation of inguinal hernias. In the case of closed vaginal process and intact internal ring, the interparietal hernia should be considered as a pre-peritoneal type. If the hernia has past through the internal ring, it is then an interstitial hernia. However, its high incidence in children and adult males suggests a relationship between the etiopathogenesis of interparietal hernia and the embryological descent of the testis, an issue that is not fully understood.

The biggest problem with the interparietal hernia is that its preoperative diagnosis is seldom, if ever. The preoperative imaging techniques play a significant role in naming of the condition. The computed tomography (CT) is the method of choice in the differential diagnosis, which can exclude the presence of an obstructing tumor. However, it is reported that both CT and herniography are not successful in differentiating the different types of inguinal hernia. ${ }^{[5,6]}$ It seems that the magnetic resonance imaging (MRI) is more sensitive and specific in differentiating the inguinal anatomy. ${ }^{[7]}$ The intraperitoneal scintigraphy has also been utilized in the diagnosis of inguinal conditions.[8] Although it is generally accepted that USG does not yield in a definite diagnosis due to tissue factors, ${ }^{[9]}$ recent studies have reported successful results with the USG in differentiating hernia types in the inguinal region.[10] 
We conclude that surgeons may sometimes come across with interparietal hernias either in the form of an odd inguinal hernia or as a case of acute intestinal obstruction of an unknown origin. Surgeons may reach to a correct preoperative diagnosis if they consider it when they have a case of unknown origin. The emergency approach to repair is straightforward once it is diagnosed.

\section{REFERENCES:}

1. Reddy KM, Stellakis MLC, Khaliq T, Fiennes AGTW. Interparietal hernia mimicking malignant small bowel obstruction. Hernia 1999; 3: 37-8.

2. Zollinger RM JR, Claasification of ventral and groin hernias. In: Fitzgibbons RJ, Greenburg AG (eds) Nyhus \& Condon's Hernia Lippincott Williams \& Wilkins, Philadelphia, pp 71-9; 2002.

3. Lower WE, Hicken NF. Interparietal Hernias. Ann Surg 1931; 94(6): 1070-1087.

4. Koot VC, de Jong JR, Perre CI. The interparietal hernia: a rare variant of an inguinal hernia. Eur J Surg 1997; 163(2): 153-155.

5. Hojer AM, Rygaard H, Jess P. CT in the diagnosis of abdominal wall hernias: a preliminary study. Eur Radiol 1997; 7(9): 1416-1418.

6. Loftus IM, Ubhi SS, Rodgers PM, Watkin DF. A negative herniogram does not exclude the presence of a hernia. Ann R Coll Surg Engl 1997; 79(5): 372-375.

7. van den Berg JC, de Valois JC, Go PM, Rosenbusch G. Dynamic magnetic resonance imaging in the diagnosis of groin hernia. Invest Radiol 1997; 32(10): 644-647.

8. Gupta SM, Bagga S, Gelfman N, Margules R. Demonstration of subclinical inguinal hernia by peritoneal scintigraphy. Clin Nucl Med 1997; 22(6): 409-410.

9. Truong SN, Jansen M. Diagnostic imaging in the evaluation and management of abdominal wall hernia. In: Fitzgibbons RJ, Greenburg AG (eds) Nyhus \& Condon's Hernia Lippincott Williams \& Wilkins, Philadelphia, pp 81-94; 2002.

10. Jamadar DA, Jacobson JA, Morag Y, Girish G, Ebrahim F, Gest T, Franz M. Sonography of inguinal region hernias. AJR Am J Roentgenol 2006; 187(1): 185-190.

\section{AUTHORS:}

1. S. Venkata Reddy

2. K. Veera Venkata Satyanarayana

3. N. S. Ayyappa Morla

\section{PARTICULARS OF CONTRIBUTORS:}

1. Associate Professor, Department of General Surgery, Rangaraya Medical College, Kakinada.

2. Assistant Professor, Department of General Surgery, Rangaraya Medical College, Kakinada.

FINANCIAL OR OTHER COMPETING INTERESTS: None
3. Senior Resident, Department of General Surgery, Rangaraya Medical College, Kakinada.

NAME ADDRESS EMAIL ID OF THE CORRESPONDING AUTHOR:

S. Venkata Reddy, \# 6-3-42, Dantu Vari Street, Kakinada-533001, Andhra Pradesh.

E-mail: venkatreddy.satti@yahoo.com

Date of Submission: 21/04/2015. Date of Peer Review: 22/04/2015. Date of Acceptance: 06/05/2015. Date of Publishing: 14/05/2015. 